\title{
Efficacy and safety of standardized short ragweed sublingual immunotherapy tablet (SLIT-T) treatment in Canadian subjects with ragweed pollen-induced rhinitis with or without conjunctivitis
}

\author{
Michael Blaiss', Peter Creticos ${ }^{2}$, Jacques Hébert ${ }^{3 *}$, Amarjot Kaur ${ }^{4}$, Harold Kim ${ }^{5,6}$, Jennifer Maloney ${ }^{4}$, Harold Nelson ${ }^{7}$, \\ Hendrik Nolte ${ }^{4}$, Susan Waserman ${ }^{6}$
}

From Canadian Society of Allergy and Clinical Immunology Annual Scientific Meeting 2013

Toronto, Canada. 3-6 October 2013

\section{Background}

Efficacy of standardized short ragweed sublingual immunotherapy tablet (SLIT-T), MK-3641 (Merck/ALK; 12 Amb a 1-U of Ambrosia artemisiifolia) treatment on Canadian ragweed-allergic subjects was assessed using subgroup analysis of data from 2 multinational, randomized, double-blind, placebo-controlled clinical trials designed to evaluate ragweed SLIT-T efficacy and safety in adults with ragweed pollen-induced allergic rhinitis with or without conjunctivitis (AR/C), with or without asthma.

\section{Methods}

We conducted pooled subgroup analysis of data from 2 studies (P05234, $\mathrm{n}=784$; P05233, $\mathrm{n}=565$ ) investigating efficacy and safety of once-daily ragweed SLIT-T $[1,2]$. In both trials, subjects were randomized to receive ragweed SLIT-T (of multiple doses tested, $12 \mathrm{Amb}$ a $1-\mathrm{U}$ was found most effective and is included here) or placebo. Treatment was started approximately 16 weeks before ragweed pollen season (RS) and continued during and after RS (total, approximately 52 weeks). Subjects recorded AR/C symptoms in daily e-diaries from randomization to end of RS. During RS, subjects also recorded AR/C rescue medication use. The primary efficacy endpoint was the average total combined score (TCS), the sum of the daily

\footnotetext{
* Correspondence: hebert.j@videotron.ca

${ }^{3}$ Centre de Recherche Appliquée en Allergie de Québec, Québec, QC, G1V 4T3, Canada

Full list of author information is available at the end of the article
}

symptom score (DSS) and daily medication score (DMS) during peak RS (the 15 consecutive days within RS with the highest 15 -day moving average pollen count).

\section{Results}

In the pooled study population of the 2 trials, approximately $80 \%$ of subjects were polysensitized and approximately $20 \%$ had asthma; mean age was approximately 36 years. The pooled Canadian subpopulation included 104 and 94 subjects receiving placebo and $12 \mathrm{Amb}$ a $1-\mathrm{U}$ SLIT-T respectively. Average pollen count for Canadian sites was approximately 100 grains $/ \mathrm{m}^{3}$ during peak RS. Canadian subjects receiving $12 \mathrm{Amb}$ a 1 -U SLIT-T had a mean TCS of 5.13 over peak RS, representing a $42 \%$ reduction vs 8.90 for placebo $(-3.77 ; 95 \% \mathrm{CI},-5.16$ to 2.39). Reductions in the primary endpoint with $12 \mathrm{Amb}$ a 1-U SLIT-T were supported by reductions in components DSS and DMS in the pooled population. Treatment-emergent adverse events (AEs) were reported for $80.9 \%$ and $94.5 \%$ of Canadian subjects in placebo and $12 \mathrm{Amb}$ a 1-U SLIT-T groups respectively; treatment-related AEs were reported for $33.9 \%$ and $80.9 \%$ respectively. The majority of treatment-related AEs were mild, local, application-site reactions with no reports of serious treatment-related AEs or systemic allergic reactions.

\section{Conclusions}

In pooled subgroup analysis from 2 trials, ragweed SLIT$\mathrm{T}$ therapy reduced symptom and medication scores in 
Canadian subjects with ragweed pollen-induced AR/C with or without asthma.

\section{Trial registration}

ClinicalTrials.gov Identifiers NCT00783198, NCT00770315.

\section{Acknowledgements}

These studies were funded by Merck, Whitehouse Station, NJ, USA. Medical writing and editorial assistance was provided by Rob Coover, MPH, of Adelphi Communications, New York, NY. This assistance was funded by Merck, Whitehouse Station, NJ, USA. Editorial assistance was also provided by Jorge Moreno-Cantu, PhD, Global Scientific and Medical Publications, Office of the Chief Medical Officer, Merck, Whitehouse Station, NJ, USA.

\section{Authors' details}

${ }^{1}$ University of Tennessee Health Science Center, Memphis, TN, 38163, USA. ${ }^{2}$ Johns Hopkins University School of Medicine, Division of Allergy \& Clinical Immunology, Baltimore, MD, 21205, USA. ${ }^{3}$ Centre de Recherche Appliquée en Allergie de Québec, Québec, QC, G1V 4T3, Canada. ${ }^{4}$ Merck, Whitehouse Station, NJ, 08889, USA. ${ }^{5}$ Western University, London, Ontario, N6A 3K7, Canada. ${ }^{6}$ McMaster University, Hamilton, Ontario, L8S 4L8, Canada. ${ }^{7}$ National Jewish Health, Denver, CO, 80206, USA.

Published: 3 March 2014

\section{References}

1. Creticos PS, Maloney J, Bernstein Dl, et al: Randomized controlled trial of a ragweed allergy immunotherapy tablet in North American and European adults. J Allergy Clin Immunol 2013, 131:1342-1349.e6.

2. Nolte H, Hébert J, Berman G, et al: Randomized controlled trial of ragweed allergy immunotherapy tablet efficacy and safety in North American adults. Ann Allergy Asthma Immunol 2013, 110:450-456.e4.

doi:10.1186/1710-1492-10-S1-A14

Cite this article as: Blaiss et al:: Efficacy and safety of standardized short ragweed sublingual immunotherapy tablet (SLIT-T) treatment in

Canadian subjects with ragweed pollen-induced rhinitis with or without conjunctivitis. Allergy, Asthma \& Clinical Immunology 2014 10(Suppl 1):A14.

\section{Submit your next manuscript to BioMed Central and take full advantage of:}

- Convenient online submission

- Thorough peer review

- No space constraints or color figure charges

- Immediate publication on acceptance

- Inclusion in PubMed, CAS, Scopus and Google Scholar

- Research which is freely available for redistribution 